Case Report

\title{
Synovial Chondromatosis with Os Trigonum
}

\author{
Marsha Rutland ${ }^{*}$ and Raustin Harris ${ }^{2}$ \\ ${ }^{1}$ Hardin-Simmons University Doctor of Physical Therapy Program, Abilene, TX, USA \\ ${ }^{2}$ US Army Base BAMC- Center, for the Intrepid, San Antonio, TX, USA
}

${ }^{\star}$ Corresponding author: Marsha Rutland, PT, ScD, MEd, OCS, COMT, CSCS Professor, Hardin-Simmons University Doctor of Physical Therapy Program, Abilene, TX, USA; Phone: 3256701337; Fax: 3256705868; Email: mrutland@hsutx.edu

Received: April 05, 2019; Accepted: April 18, 2019; Published: April 20, 2019;

\section{Case}

A 25-year old male physical therapist had severe right ankle pain immediately following a workout with lunges, drop jumps, and single leg hops. The patient reported 10/10 anterior and posterior ankle pain and was unable to run or fully weight bear immediately or for the next 24-hours. The patient had a long history of multiple inversion sprains resulting in ankle pain and edema throughout his prior high school/ college football career.

Motion loss of 10 degrees in dorsiflexion/plantarfexion resulting in a reduced stance, stride, and push-off (antalgic gait) was evident. Palpation tenderness was noted over the anterior talus and distal tibia. The patient referred himself to an orthopedic physician two days following the injury due to the palpatory tenderness over the anterior distal tibia and pain with weight bearing (Ottawa Ankle Rules) [1].
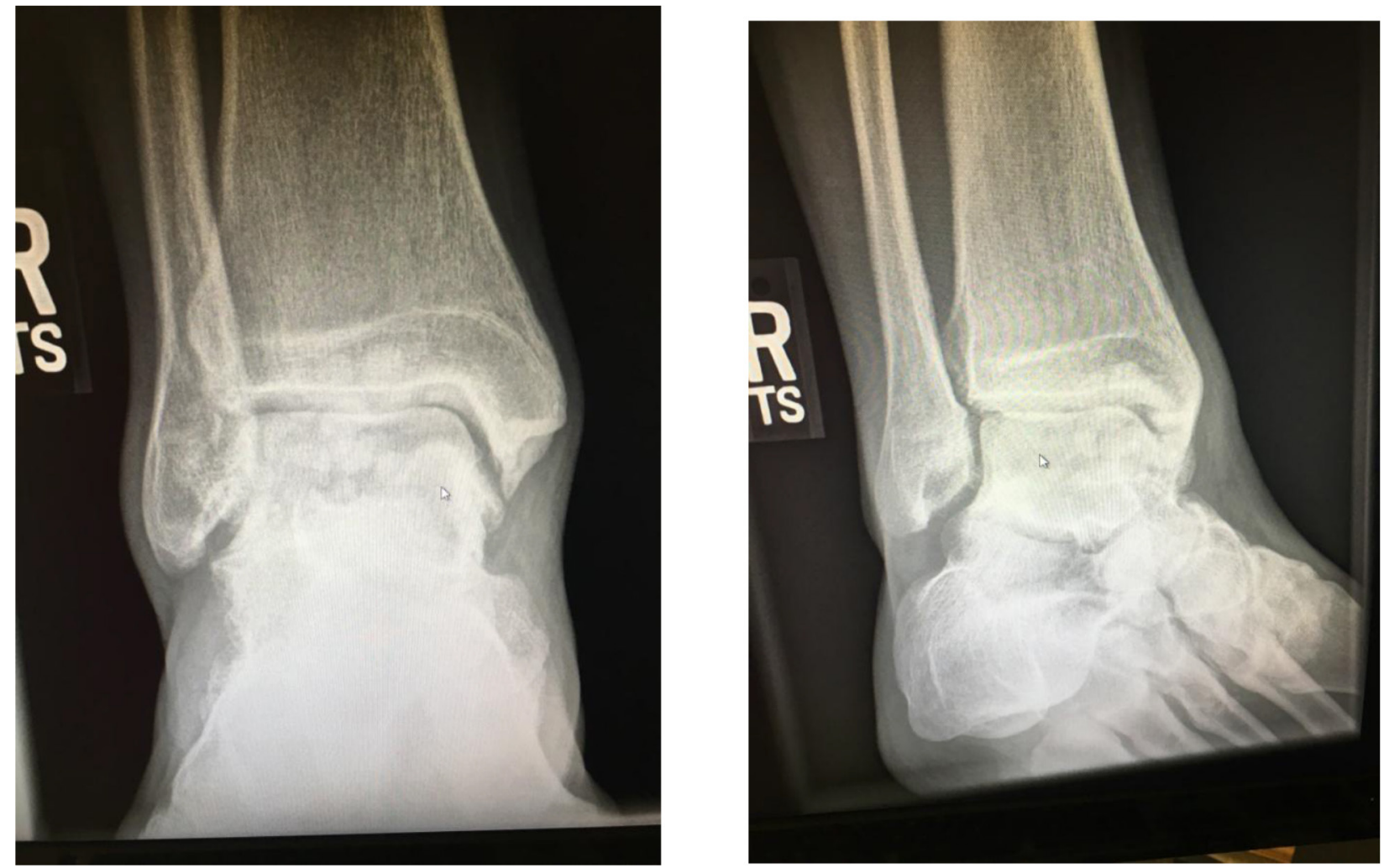

Figure 1. Anterior- posterior and Mortise view radiographs of the right ankle. Some small chondromatosis is seen in mid area of distal tibia and talus.
No evidence of a fracture was noted on the anterior-posterior or mortise radiographic views of the ankle (Figure 1). Synovial chondromatosis [2], or "popcorn" was present on both anteriorposterior and lateral views. Os trigonum [3] (an accessory ossicle) was also present between the posterior talus and calcaneus (Figure 2). MRIs confirmed radiographic findings. The patient was referred to an orthopedic ankle surgeon for an arthroscopic resection of the os trigonum and synovial osteochondromatosis 3-weeks post-injury date. The patient wore a CAM boot for 2-weeks at WBAT status and resumed full weight bearing ambulation at 3-weeks post-op without residual pain or dysfunction. He resumed running at 2-months postsurgery without pain. 


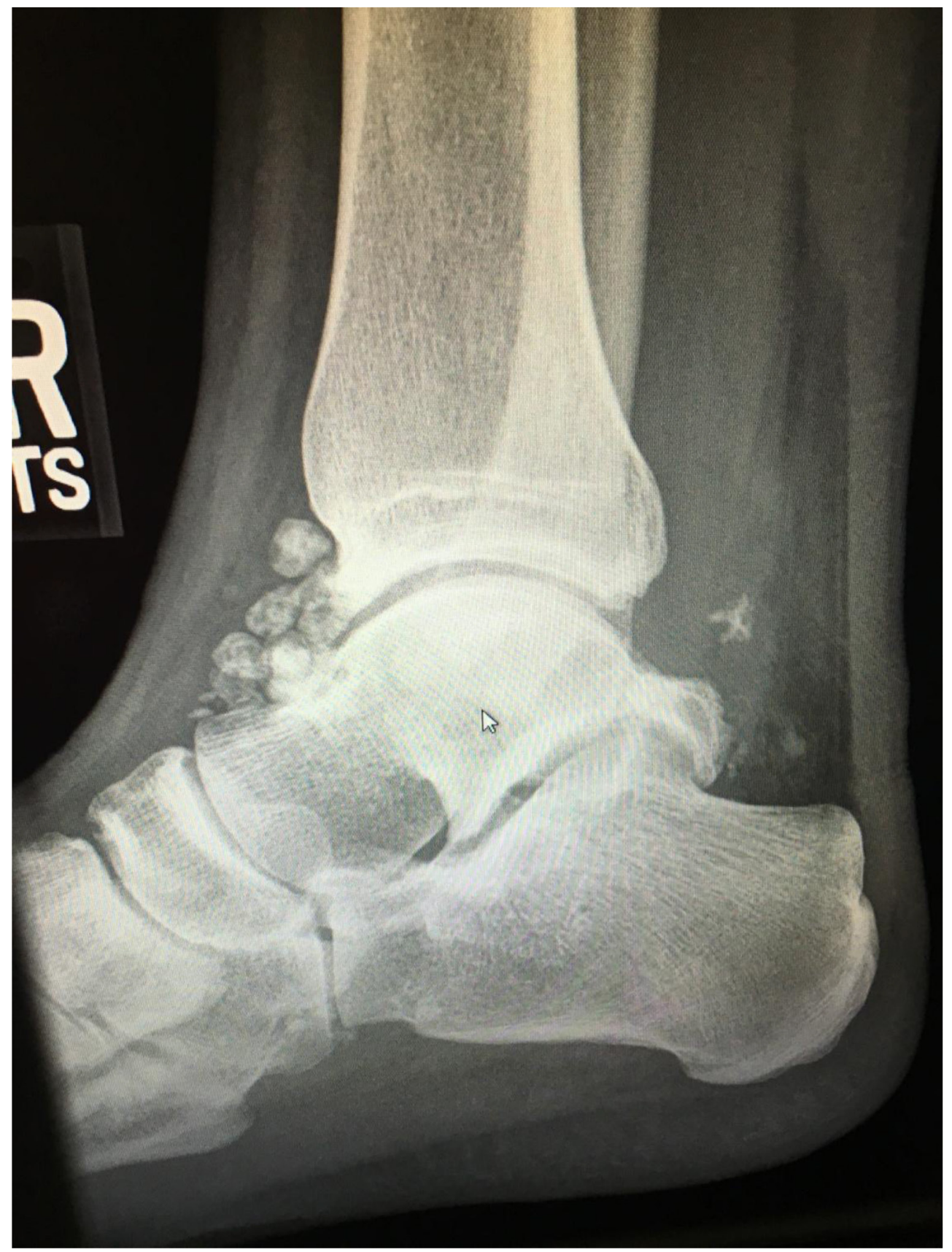

Figure 2. Lateral view radiograph of right ankle, demonstrating significant synovial chondromatosis in the anterior aspect of the tibia and talus. Os trigonum is also present between the posterior talus and calcaneous.

\section{References}

1. Stiell IG, McKnight RD, Greenberg GH, et al (1994) Implementation of the Ottawa ankle rules. J Am Med Assoc 271:827-832. [Crossref]

2. Sedeek SM, Choudry Q, Garg S (2015) Synovial chondromatosis of the ankle joint: clinical, radiological, and intraoperative findings. Case Rep Orthop. 2015.

3. D'Hooge P, Alkhelaifi K, Almusa E Tabben M, Wilson MG, Kaux JG (2018) Chronic lateral ankle instability increases the likelihood for surgery in athletes with os trigonum syndrome. Knee Surg Sports Traumatol Arthrosc 2018.

\section{Citation:}

Rutland M, Harris R (2019) Synovial Chondromatosis with Os Trigonum. Integr J Orthop Traumatol Volume 2(2): 1-2. 